\title{
PRODUÇÃO MAIS LIMPA: DIAGNÓSTICO PARA POSSÍVEL IMPLANTAÇÃO EM UMA PANIFICADORA LOCALIZADA NA CIDADE DE BELÉM - PA
}

Wilian Victor da Silva Campos - wiliancampos17@ hotmail.com Engenheiro ambiental

Juliane da Costa Cavalcante - julianecosta63@ gmail.com Engenheira ambiental

Danielle de Lima Farias - danielle.ambiental@ hotmail.com Engenheira ambiental

Jailson Soares de Souza Filho - engsoaresfilho@ gmail.com Engenheiro ambiental

Karla Karoline Leite do Rosário - karlaleite93@ gmail.com Engenheira ambiental

Luciana Haydemar Ferreira Ramos - lucianahayde@ hotmail.com Engenheira ambiental Nicole de Lima Silva - nicoledilima@gmail.com Engenheira ambiental Walber Lopes de Oliveira - walberlopez@live.com Engenheiro ambiental 


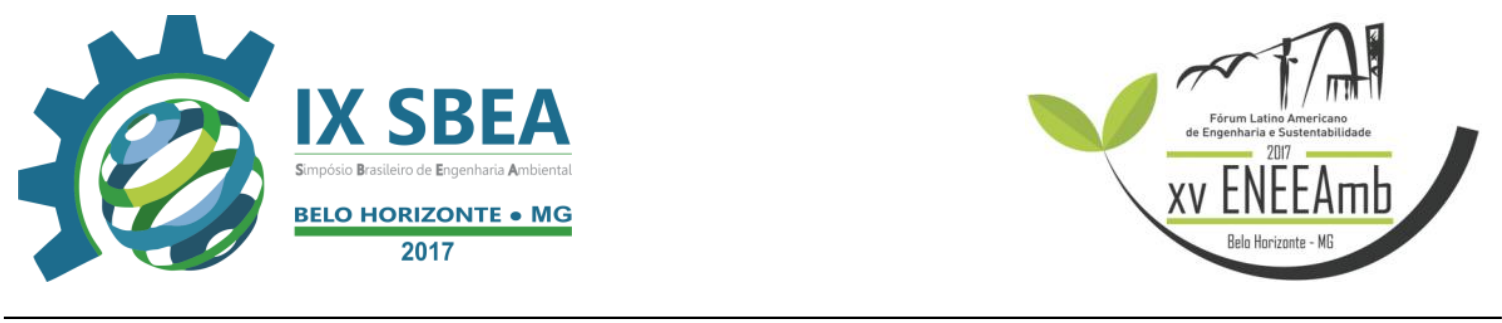

\section{RESUMO}

A Produção mais Limpa (PmaisL) tem como finalidade minimizar e/ou eliminar a geração de resíduos na fonte provocados pela cadeia de produção. Objetivou-se através desse artigo diagnosticar a situação dos resíduos gerados no processo produtivo de uma panificadora localizada em Belém - PA. Foram realizadas visitas ao local para analisar o processo de produção e os resíduos sólidos e líquidos gerados no estabelecimento. Os resultados sugerem que há possibilidade de implantação da PmaisL na panificadora com o objetivo de otimizar o processo produtivo, evitando gerar o mínimo de resíduos possíveis.

Palavras-chave: PmaisL, Resíduos Sólidos, Ecoeficiencia.

\section{INTRODUÇÃO/OBJETIVO}

O crescimento da atividade de panificação no Brasil e a evolução na tecnologia dos processos produtivos são fatores que podem ocasionar impactos significativos ao meio ambiente, com destaque para a geração de resíduos sólidos (PIMENTA \& MARQUES JÚNIOR, 2006). De acordo com o SEBRAE NACIONAL (2009), aproximadamente 63,2 mil panificadoras participam do mercado da panificação e confeitaria no Brasil, das quais 60 mil são micros e pequenas empresas.

Para minimizar os possíveis impactos ambientais relacionados a atividade algumas estratégias ambientais estão surgindo ou adaptando-se. Entre elas a produção mais limpa, ou PmaisL, que é a aplicação contínua de uma estratégia ambiental preventiva e integrada, nos processos produtivos, nos produtos e nos serviços, para reduzir os riscos relevantes aos seres humanos e ao ambiente natural (UNEP, 2006).

Objetivou-se realizar um estudo de aplicação da estratégia ambiental PmaisL em uma panificadora em Belém- PA. Justificado pela a adequação ambiental, obrigatória, de todos os empreendimentos que possam gerar algum impacto ao meio ambiente.

\section{METODOLOGIA}

Como primeiro passo antes da implementação do programa de PmaisL no empreendimento, realizou-se uma visita técnica para firmar o acordo e, ao mesmo tempo, pré-sensibilizar os proprietários sobre o tema. Assim como realizar uma pré-avaliação do empreendimento e da produção. 


\section{Obtenção do Comprometimento Gerencial}

Foram realizadas reuniões de curta duração com proprietários da panificadora, visando a conscientização acerca do programa, assim como o comprometimento dos mesmos.

\section{Sensibilização dos funcionários}

Houve a necessidade de apresentar aos colaboradores o programa e mostrar a importância do comprometimento dos mesmos, visto que estes são os agentes executores da produção. Então, foram pré-definidas tarefas e metas para cada funcionário.

\section{Formação do ECOTIME}

A empresa possui 2 sócios proprietários e emprega 6 funcionários que efetuam atividades relacionadas à fabricação de panificados, atendimento ao cliente e serviços gerais.

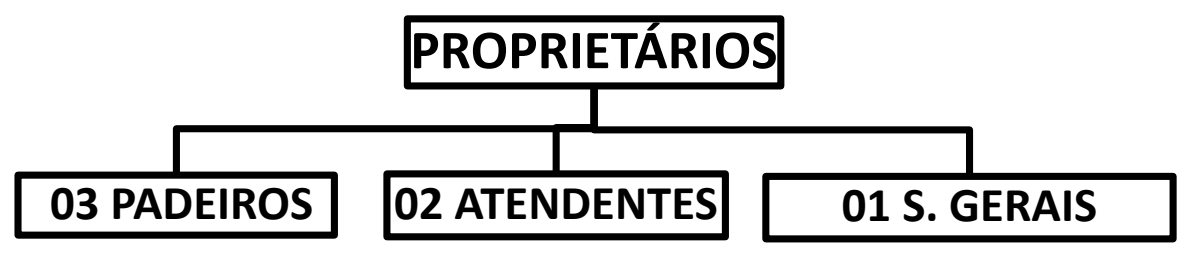

Foram selecionadas três pessoas para compor o ECOTIME, as quais se mostraram mais pró-ativas e interessadas no desenvolvimento do programa: um proprietário e dois funcionários que exercem a função de padeiro.

\section{Apresentação da Metodologia}

Após a formação do ECOTIME, foram marcadas pequenas reuniões com o intuito de apresentar os objetivos e metas do programa aos colaboradores e motivá-los para que eles disseminassem as etapas da atividade com o restante dos funcionários e também obtivessem deles o apoio, no que diz respeito à execução das ações dentro dos objetivos e metas estipulados.

Para a concretização da Produção mais Limpa os funcionários trabalharam com ações voltadas para a redução. Reduções no desperdício de matéria prima, consumo de água, energia elétrica, geração de resíduos sólidos e líquidos e sacolas plásticas. Além de tais reduções, o empenho em adequar o empreendimento à legislação ambiental e realizar o seu Licenciamento Ambiental. 

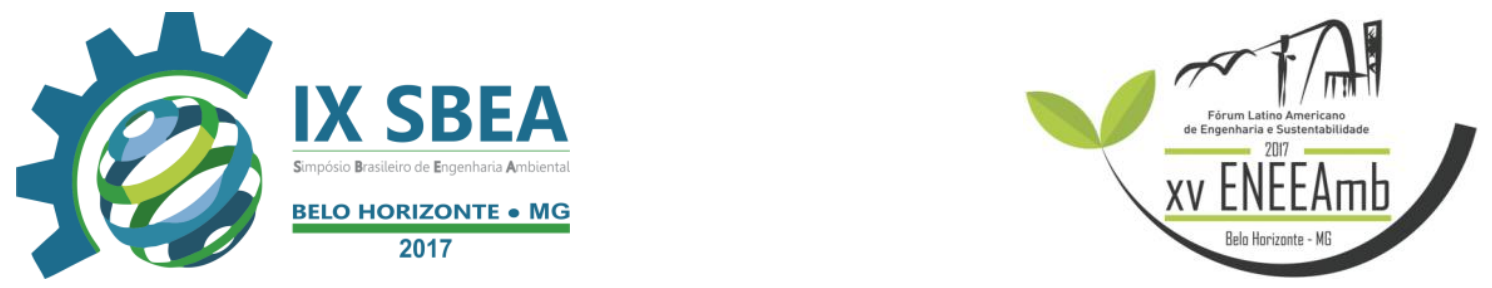

\section{RESULTADOS E DISCUSSÃO}

\section{Pré-avaliação}

$\mathrm{Na}$ fase de pré-avaliação foi possível levantar as seguintes informações: (1) A panificadora não possui licença ambiental; (2) Não há segregação de resíduos, então não há revenda de materiais recicláveis; (3) Sobras de produção são divididas entre os funcionários no final do expediente, então não fazem parte dos resíduos do empreendimento, e (4) Os efluentes gerados no local são oriundos do banheiro e limpeza/lavagem da panificadora e de equipamentos.

Os principais compartimentos estudados são: (1) Local de Produção: Onde encontram-se os seguintes equipamentos: masseira, modelador de massa, forno, fogão e mesa, além de um local de lavagem e um pequeno deposito; (2) Local onde os produtos são colocados em exposição nas estufas e onde há mesas e cadeiras para acomodação dos clientes Figura 01.

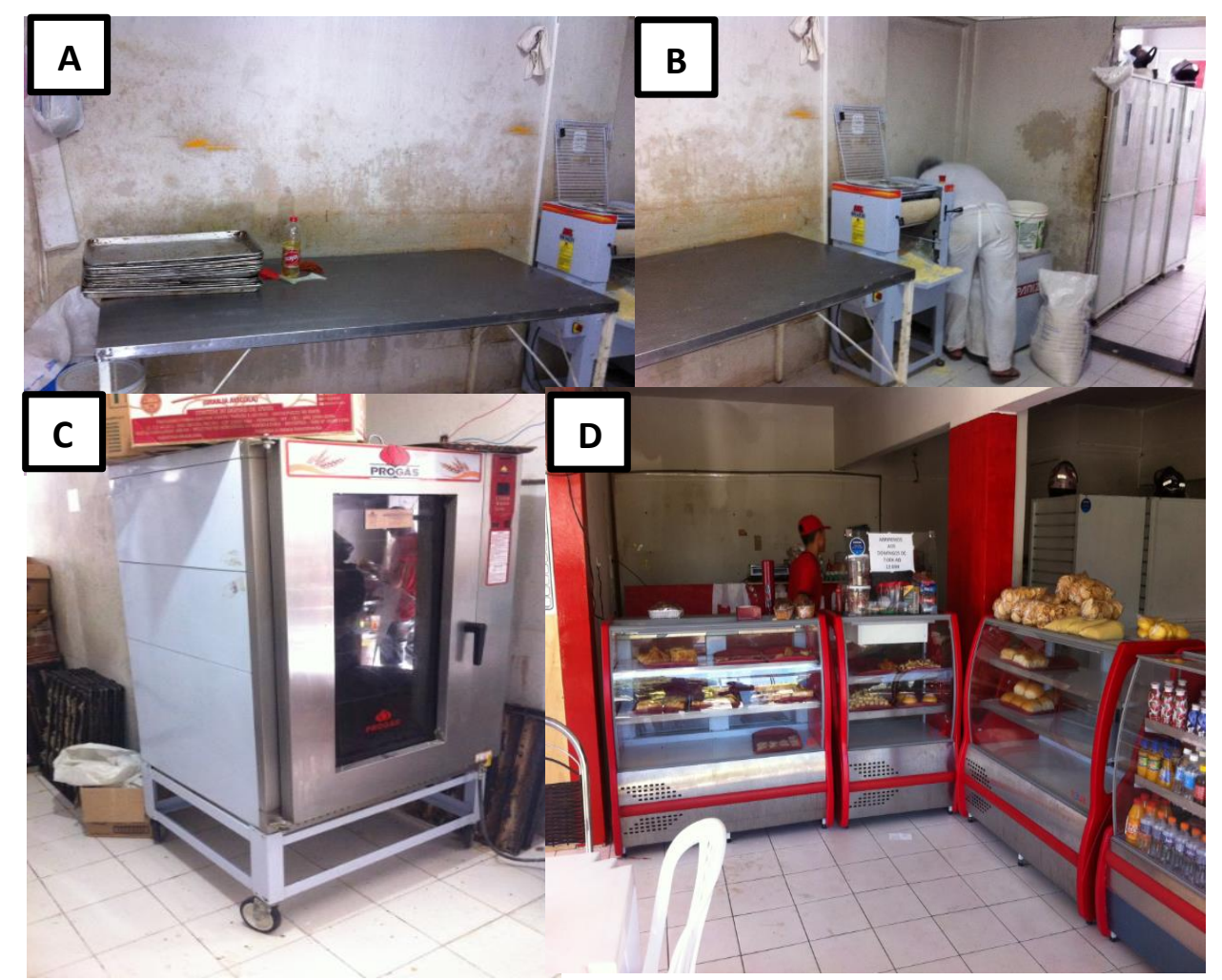

Figura 01: Estabelecimento. Legenda: (A, B e C) Local de produção; (D) Área de venda e exposição de produtos. 


\section{Elaboração de Fluxogramas}

Este trabalho abrange principal produto do empreendimento (pães) e, consequentemente, seu processo produtivo. O fluxograma foi construído e organizado levando em consideração o processo de fabricação de pães, sendo estruturado em seis etapas: (1) Preparação de Insumos; (2) Batedeira; (3) Corte e Pesagem de Porções; (4) Descanso e Fermentação; (5) Forno, e (6) Balcão de Venda.

É importante destacar que cada etapa deste processo possui uma entrada através de insumos onde a transformação resultará em uma saída, originando um bem de valor, assim como, poderá resultar em resíduos dentro do sistema. Para exemplificar essas situações foi elaborado o fluxograma qualitativo global, que trata do processo produtivo da panificadora Figura 02.

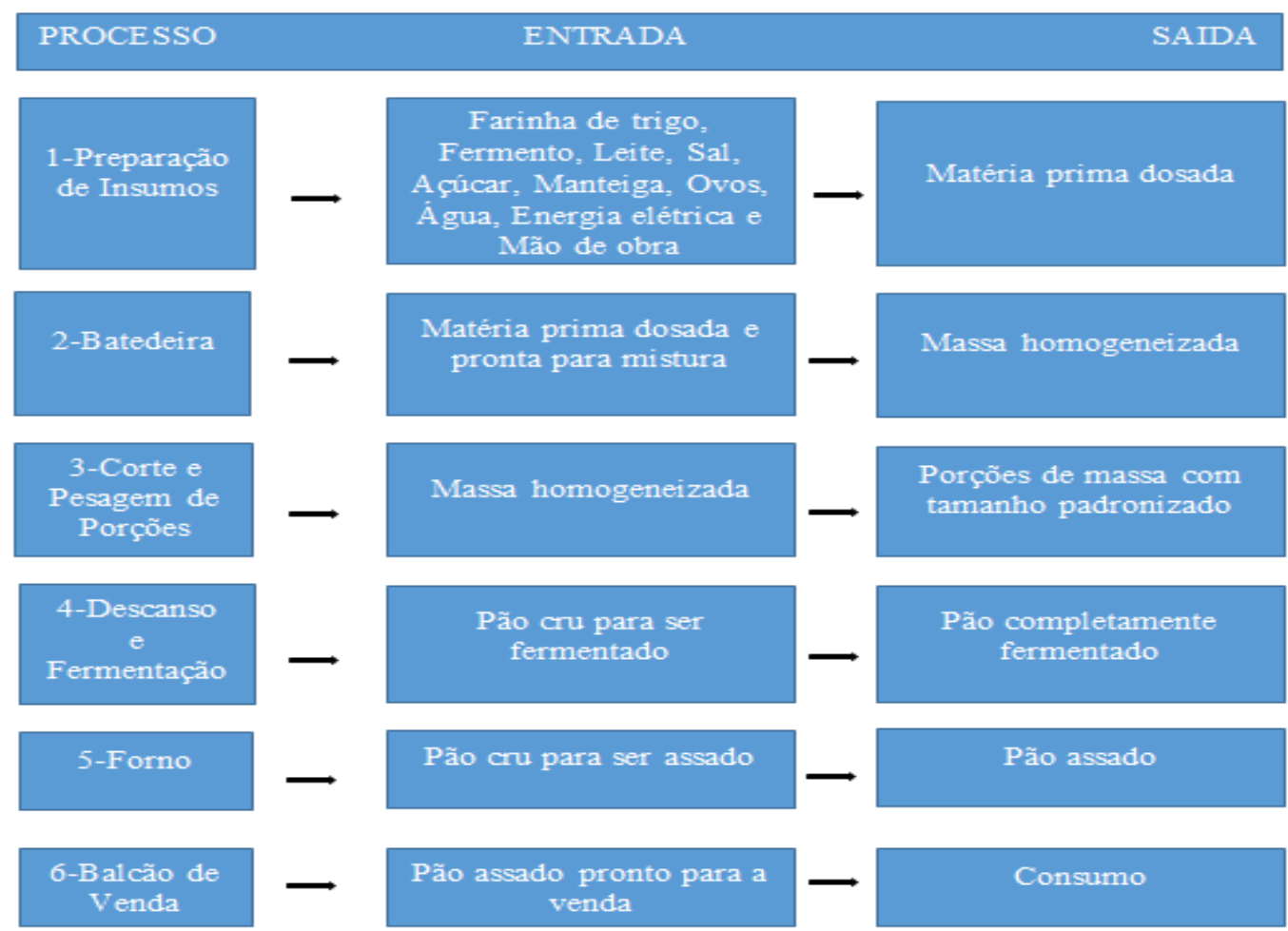

Figura 02: fluxograma qualitativo global.

E o fluxograma qualitativo intermediário que aborda o resíduo de cada etapa de produção. É importante ressaltar a inclusão da etapa de limpeza e lavagem de equipamentos e empreendimento no fluxograma qualitativo intermediário, caracterizando um produtor de efluente líquido. Figura 03. 

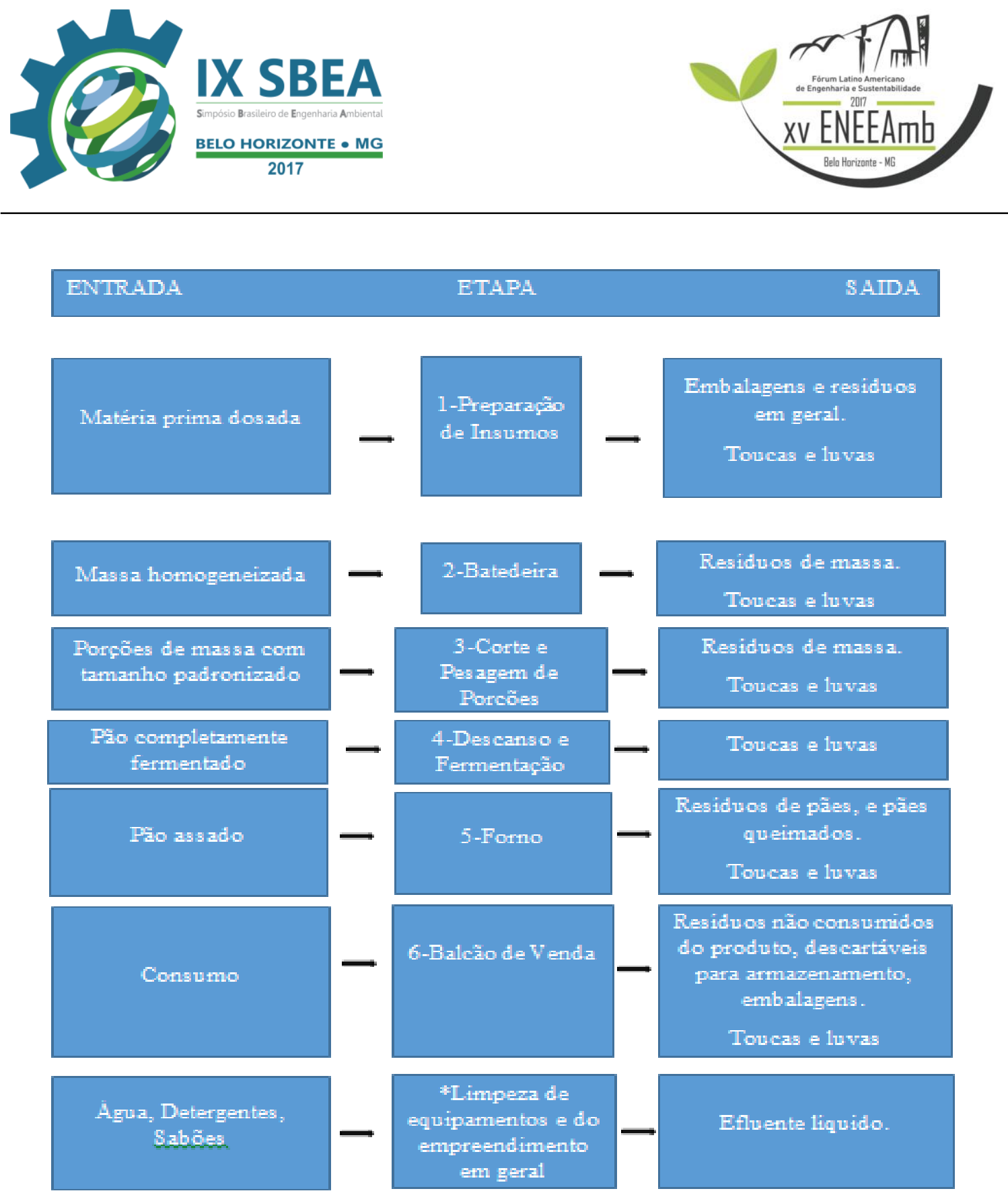

Figura 03: fluxograma qualitativo intermediário com entradas e saídas de resíduos.

\section{Tabelas Quantitativas}

Através dos dados disponíveis, foi possível montar a tabela quantitativa de cada material utilizado no processo produtivo da panificadora bem como de materiais auxiliares como EPIs e materiais de limpeza, considerando fatores como, por exemplo, a etapa do processo de cada material, a quantidade de material utilizada por ano, o custo unitário de compra, o custo total para a empresa e a participação do material no produto final. Além destes, também foi considerado o consumo e o custo da água e de energia elétrica utilizado como mostra a Tabela 1. 
Tabela 1: Global: Matérias-primas e auxiliares

\begin{tabular}{|c|c|c|c|c|c|c|}
\hline $\begin{array}{c}\mathrm{N}^{\circ} \\
\text { etapa }\end{array}$ & Material & $\begin{array}{c}\text { Quantidade } \\
\text { por ano }\end{array}$ & Unidade & $\begin{array}{c}\text { Custo } \\
\text { unitário de } \\
\text { compra }(\mathbf{R} \$)\end{array}$ & $\begin{array}{c}\text { Custo } \\
\text { total }(R \$)\end{array}$ & $\begin{array}{c}\text { Participação no } \\
\text { total do produto } \\
\%\end{array}$ \\
\hline 1 & $\begin{array}{l}\text { Farinha de } \\
\text { trigo }\end{array}$ & 34.560 & $\mathrm{Kg}$ & 2,5 & 86.400 & 100 \\
\hline 1 & Fermento & 91,25 & $\mathrm{Kg}$ & 7,5 & 684,375 & 100 \\
\hline 1 & Leite & 730 & $\mathrm{Kg}$ & 11 & $8.030,00$ & 100 \\
\hline 1 & Sal & 292 & $\mathrm{Kg}$ & 1,5 & 438,00 & 100 \\
\hline 1 & Açúcar & 912,5 & $\mathrm{Kg}$ & 2,5 & 2281,25 & 100 \\
\hline 1 & Manteiga & 547,5 & $\mathrm{Kg}$ & 11 & 6022,5 & 100 \\
\hline 1 & Ovos & 16.790 & 46 Unid. & 0,45 & 7555,5 & 100 \\
\hline 1 & Água & 1.095 & Litro & 3,5 & 3832,5 & 100 \\
\hline 1 & $\begin{array}{l}\text { Energia } \\
\text { elétrica }\end{array}$ & $6.000,00$ & $\mathrm{kw} / \mathrm{h}$ & 0,7415 & $4.449,00$ & 100 \\
\hline 1 & Luvas & 2.190 & 6 Unid. & 0,12 & 262,8 & Não se aplica \\
\hline 1 & Toucas & 2.190 & 6 Unid. & 0,08 & 175,2 & Não se aplica \\
\hline 3 e 6 & Queijo & 912,5 & $\mathrm{Kg}$ & 14 & $12.775,00$ & 100 \\
\hline 3 e 6 & Presunto & 438 & $\mathrm{Kg}$ & 18 & $7.884,00$ & 100 \\
\hline 3 e 6 & Salsicha & 182,5 & $\mathrm{Kg}$ & 12 & $2.190,00$ & 100 \\
\hline 6 & $\begin{array}{l}\text { Sacolas/des } \\
\text { cartáveis }\end{array}$ & 72.000 & Unid. & 0.05 & $3.600,00$ & Não se aplica \\
\hline$*$ & Água & 288 & $\mathrm{~m}^{3}$ & 2,68 & 771,84 & Não se aplica \\
\hline$*$ & Sabão & 91,25 & $\mathrm{Kg}$ & 7,5 & 684,3 & Não se aplica \\
\hline$*$ & Detergente & 109,5 & Litro & 9,5 & 1040,25 & Não se aplica \\
\hline
\end{tabular}

*Vide fluxograma qualitativo intermediário.

Após a realização de uma triagem de materiais feita pela equipe de trabalho na panificadora, também foi elaborada uma tabela da quantidade de materiais recicláveis que poderiam ser reaproveitados Tabela 2. 
Tabela 2: Preço dos materiais recicláveis

\begin{tabular}{|c|c|c|c|}
\hline $\begin{array}{c}\text { RESÍDUOS } \\
\text { RECICLÁVEIS }\end{array}$ & $\begin{array}{c}\text { QUANTIDADE } \\
\text { POR ANO (Kg) }\end{array}$ & $\begin{array}{c}\text { VALOR } \\
\text { COMERCIAL (R\$) }\end{array}$ & $\begin{array}{c}\text { APURAÇÃO } \\
\text { PREVISTA (R\$) }\end{array}$ \\
\hline Plástico & $120 \mathrm{Kg}$ & 0,2 & 24 \\
\hline Papelão & $200 \mathrm{Kg}$ & 0,08 & 16 \\
\hline Papel & $210 \mathrm{Kg}$ & 0,15 & 31,5 \\
\hline Metal & $300 \mathrm{Kg}$ & 0,5 & 150 \\
\hline
\end{tabular}

Adaptado de PIMENTA \& MARQUES JÚNIOR, 2009.

\section{Definição de Indicadores}

Com base nos dados levantados foi possível definir indicadores para o monitoramento da PmaisL na panificadora, de acordo com a Tabela 3.

Tabela 3: Indicadores de monitoramento

\begin{tabular}{|c|c|c|}
\hline \multicolumn{2}{|c|}{$\begin{array}{l}\text { Consumo de água } \mathrm{m}^{3} / \mathrm{kg} \text { de } \\
\text { produto produzido } \\
1.095 \mathrm{~L} / 58.060 \mathrm{Kg}\end{array}$} & 0,01 L / kg de produto \\
\hline \multirow{8}{*}{$\begin{array}{l}\text { Matéria-prima/Kg de } \\
\text { produto produzido. } \\
41.245 \mathrm{Kg} / 58.060 \mathrm{Kg}\end{array}$} & Trigo & \multirow{8}{*}{ 0,71039KgMP / Kg de produto } \\
\hline & Fermento & \\
\hline & Leite & \\
\hline & Frios & \\
\hline & & \\
\hline & Açúcar & \\
\hline & Manteiga & \\
\hline & Ovos & \\
\hline \multicolumn{2}{|c|}{$\begin{array}{l}\text { Resíduo sólido gerado / Kg de } \\
\text { produto produzido: } \\
1080 \mathrm{Kg} / 58,060 \mathrm{~T}\end{array}$} & $\begin{array}{c}0,0186 \mathrm{Kg} \text { de resíduo sólido gerado/kg de } \\
\text { produto }\end{array}$ \\
\hline \multicolumn{2}{|c|}{$\begin{array}{l}\text { Efluente líquido gerado } \mathrm{m}^{3} / \mathrm{Kg} \text { de } \\
\text { produto produzido: } \\
288 \mathrm{~m}^{3} / 58.060 \mathrm{~T}\end{array}$} & $0,004 \mathrm{~m}^{3} / \mathrm{Kg}$ de produto \\
\hline
\end{tabular}




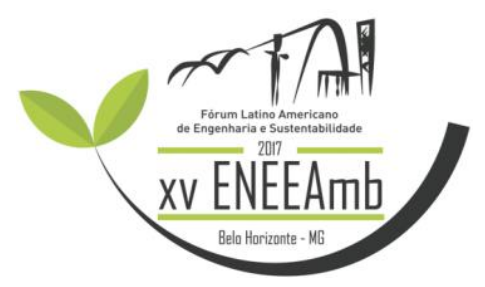

\section{Custo de disposição de efluente \\ Não há disposição de efluentes. \\ ( $\mathrm{R} \$ / \mathrm{Kg}$ de resíduo produzido) \\ Custo de tratamento de efluente \\ Não há tratamento de efluentes. \\ $\left(\mathrm{R} \$ / \mathrm{m}^{3}\right.$ de efluente produzido)}

\section{Avaliação de Dados Coletados}

A análise de dados foi realizada a partir do preenchimento das tabelas quantitativas, onde se pode analisar os resíduos gerados e valorar seus custos para a empresa. A Tabela 4 exibe a quantidade (em $\mathrm{kg}$ ) de resíduos recicláveis produzidos e desperdício de matéria-prima no processo de fabricação dos produtos da panificadora, bem como o custo que cada um desses representa para a empresa.

A primeira análise a ser feita está relacionada com as embalagens da matériaprima, que são, em geral, saco de trigo, açúcar, sal, embalagens plásticas de manteiga, fermento, embalagens metálicas de achocolatado, materiais orgânicos como casca de ovo, entre outros. A quantificação dos resíduos foi feita ao final do expediente e quantificados em $3 \mathrm{~kg} /$ dia (1.095 kg/ano), de acordo com a Tabela 4, a análise do custo não foi realizada, pois a empresa não apresenta custos com a disposição ou transporte desses resíduos, visto que são destinados pela coleta do município de Belém.

A segunda análise está voltada para a farinha de trigo, principal matéria-prima utilizada na panificadora, em visita ao estabelecimento foi observado que havia resíduos de farinha trigo desperdiçados, tanto na linha de produção da empresa como nos equipamentos e no manuseio desta. Diante disso, para quantificar os chamados resíduos de farinha de trigo, adotou-se um valor estimado para essa perda calculada em $2 \%$ ao ano em cima da quantidade total de farinha de trigo utilizada pela empresa que é de 34.560 $\mathrm{kg} / \mathrm{ano}$, representando um custo total de $1.728,00$ reais ao ano para a empresa, de acordo com a tabela abaixo Tabela 4.

A análise referente à massa pronta (produtos fabricados na padaria, como: pães, biscoitos, salgados e outros), observou-se que a produção diária que sobra ao final do expediente, são autorizados aos funcionários levar para seu próprio consumo ou doados, além de sobras de massa referente ao processo produtivo e equipamentos utilizados. Segundo o proprietário do estabelecimento, são produzidos, aproximadamente, 161,28 


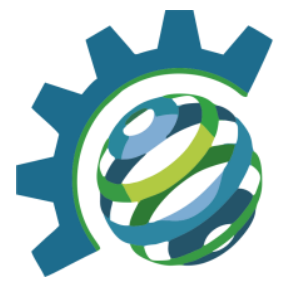

$\mathrm{kg} /$ dia de massa pronta, para fazer uma análise da quantidade de resíduos de massa pronta produzida por ano foi adotado um valor estimado para essa perda de $2 \%$ ao ano, chegando a um total de $1.177,34 \mathrm{~kg}$ de massa pronta desperdiçada por ano Tabela 4.

Tabela 4: Análise de quantidade versus custo total

\begin{tabular}{|c|c|c|}
\hline & $\begin{array}{c}\text { ANÁLISE DE } \\
\text { QUANTIDADE }\end{array}$ & $\begin{array}{c}\text { ANÁLISE DE } \\
\text { CUSTO }\end{array}$ \\
\hline Resíduos e matéria-prima & Quantidade em Kg/ano & $\begin{array}{c}\text { Custo total do } \\
\text { resíduo R\$ por ano }\end{array}$ \\
\hline $\begin{array}{c}\text { Embalagens da matéria prima } \\
\text { (plástico, papelão e metálica) }\end{array}$ & 1.095 & $\mathrm{X}$ \\
\hline Resíduos de farinha de trigo & & $1.728,00$ \\
\hline Resíduo de massa pronta & $1.177,34$ & $10.831,52$ \\
\hline
\end{tabular}

Tendo em vista os desperdícios, e a necessidade de regularização ambiental, umas das prioridades de avaliação é a redução do desperdício de matéria prima, que também reflete em ganhos econômicos. É importante ressaltar que os custos apresentados foram estimados de acordo com observações realizadas em visita a empresa. E muitas vezes os custos apresentados não são notados pelo empreendedor.

\section{Barreiras}

O processo de implantação do método $\mathrm{P}$ mais $\mathrm{L}(\mathrm{P}+\mathrm{L})$ dentro do estabelecimento, objeto de análise deste estudo, é seguido por uma série de barreiras que foram identificados nas diferentes etapas de elaboração do plano. Não obstante, as limitações encontradas demonstraram oportunidades de melhorias que podem ser expressas em resultados positivos de aspectos financeiros, ambientais e gerencias a curto, médio e longo prazo.

Os resultados encontrados por meio de entrevistas com os proprietários da panificadora e acompanhamentos do processo produtivo foram fundamentais para visualizar obstáculos, dentre ele podemos citar: (1) Barreiras relacionadas a política: carência de regularização ambiental, falta de incentivo econômico; (2) Relacionadas com o mercado: falta de demanda por ecoeficiência, pequena pressão e conscientização 
pública; (3) Relacionadas a informações técnicas: limitada capacitação e especialização, acesso ao apoio técnico externo, informações em $\mathrm{P}+\mathrm{L}$, treinamento técnico no local de trabalho e (4) Falta de consciência sobre benefícios e capacidade gerencial inadequada;

\section{CONCLUSÕES/RECOMENDAÇÕES.}

A produção mais limpa é uma prática de fundamental importância para as organizações, já que essencialmente busca a otimização dos recursos, evitando emitir efluentes para o meio ambiente, devido a utilização de tecnologias modernas, bem como, da conscientização ambiental da organização. Além disso, com a prática da $\mathrm{P}$ mais L é possível diminuir os riscos, evitando a geração de resíduos, usando a matéria-prima, a energia e a água de forma mais eficiente, uma vez que a água é um recurso escasso na natureza. Por meio desta técnica a Panificadora estudada pode apresentar ganhos significativos no ponto de vista ambiental, econômico e gerencial, destacando-se dentre os demais estabelecimentos do mesmo segmento.

\section{REFERÊNCIAS BIBLIOGRÁFICAS}

\section{CONSELHO EMPRESARIAL BRASILEIRO PARA O DESENVOLVIMENTO} SUSTENTÁVEL. Guia de produção mais limpa. Disponível em: http://cebds.org/publicacoes/guia-para-producao-mais-limpa-faca-vocemesmo/\#.WPAPpdLyvIU. Acesso em: 20 de nov. 2016.

PIMENTA, Handson Cláudio Dias \& MARQUES JÚNIOR, Sérgio. Modelo de gerenciamento de resíduos sólidos: um estudo de caso na indústria de panificação em Natal-RN. In: XXVI ENEGEP. Fortaleza, 2006. p. 1-10

SEBRAE NACIONAL - BR. Perfil Setorial da Indústria de Panificação - 2009. Serviço Brasileiro de Apoio a Micros e Pequenas Empresas. Disponível em: http://www.sebrae.com.br. Acesso em: 13 de ago. 2016.

UNEP (ONU), 2011. Understanding Cleaner Production. Disponível em: http://www.uneptie.org/pc/cp/understanding_cp/home.htm. Acesso em: 20 de ago. 2016. 